Original article

\title{
Chest radiographic findings and clinical determinants for severe pulmonary tuberculosis among children and adolescents in Malaysia
}

\author{
Hafizuddin Awang ${ }^{1}$, Nik Rosmawati Nik Husain ${ }^{1}$, Hasniza Abdullah ${ }^{2}$ \\ ${ }^{1}$ Department of Community Medicine, School of Medical Sciences, Universiti Sains Malaysia, Kelantan, Malaysia. \\ ${ }^{2}$ Tuberculosis and Leprosy Control Unit, Kelantan State Health Department, Kelantan, Malaysia.
}

Received 13 June 2018, Revised 26 September 2018, Accepted 21 January 2019

(C) 2018, Awang H., Nik Husain N.R., Abdullah H.

(C) 2018, Russian Open Medical Journal

Abstract: Aim - This study aimed to describe the characteristic of chest radiographic findings at diagnosis in children with pulmonary tuberculosis and to determine the clinical determinants for severe pulmonary tuberculosis among children and adolescents in Kelantan, a northern state of Peninsular Malaysia from 2012 until 2015.

Material and Methods - This was a comparative cross-sectional study between mild and severe pulmonary tuberculosis patients according to chest radiographic findings among children and adolescents using Tuberculosis Information System as a source population. All notified cases that fulfilled the inclusion and exclusion criteria were included in the study. Descriptive statistics, simple and multiple logistic regressions were used for data analysis.

Results - Out of 388 pulmonary tuberculosis radiographs, majority had minimal lesion (69.8\%), followed by moderately advanced lesion (23.5\%), no lesion (4.9\%) and lastly, far advanced lesion (1.8\%). Clinically among the severe form of pulmonary tuberculosis, none was human immunodeficiency virus (HIV) positive, $23.5 \%$ smokers, $19.4 \%$ had no Bacillus Calmette-Guerin (BCG) scar and $72.4 \%$ had positive pre-treatment Acid-Fast Bacilli (AFB) sputum smear. In multiple logistic regression, cigarette smoking (adjusted odds ratio (AOR) 1.43, 95\% confidence interval $(\mathrm{Cl})$ : 1.21-3.61, $\mathrm{p}=0.03$ ), positive sputum AFB smear (AOR 2.32, 95\% Cl: 1.29-4.13, $p=0.004)$ and absent $B C G$ scar $(A O R$ $1.24,95 \% \mathrm{Cl}: 1.12-8.04, \mathrm{p}=0.002)$ were significantly associated with severe pulmonary tuberculosis.

Conclusion - In conlusion, majority of pulmonary tuberculosis in children and adolescents were of mild severity in Kelantan. Cigarette smoking, pre-treatment positive sputum AFB smear and absent BCG scar were important clinical determinants for severe pulmonary tuberculosis. Hence, the study provides information that would assist in prevention of severe pulmonary tuberculosis in children and adolescents.

Keywords: pulmonary tuberculosis severity, children and adolescents, chest radiograph.

Cite as Awang $\mathrm{H}$, Nik Husain NR, Abdullah $\mathrm{H}$. Chest radiographic findings and clinical determinants for severe pulmonary tuberculosis among children and adolescents in Malaysia. Russian Open Medical Journal 2019; 8: e0210.

Correspondence to Assoc. Prof. Dr. Nik Rosmawati Nik Husain. Address: Department of Community Medicine, School of Medical Sciences, Universiti Sains Malaysia, 16150 Kelantan, Malaysia. Email: rosmawati@usm.my. Phone: +609-7673000.

\section{Introduction}

Tuberculosis is a major public health problem globally with an estimated 10.4 million new tuberculosis cases in 2015 and approximately 1 million children contracted tuberculosis each year [1, 2]. A 2016 study projected that 67 million children and adolescents have latent tuberculosis, with about 850,000 developing active tuberculosis every year. Malaysia is a country located in the South-East Asia region with 31 million people. Malaysia's population comprises many ethnic groups. The state of Kelantan is located in the northeast of Peninsular Malaysia and its people is made up of majorly Malay ethnic population (95.7\%) [3]. The Western Pacific Region, of which Malaysia is part of it, accounted for nearly $60 \%$ of the world's tuberculosis cases in 2012. Our adjacent neighbours Indonesia, the Philippines and Thailand were the three of the 22 countries with the world's highest tuberculosis burden [2]. In Malaysia, recent report from Malaysian Ministry of Health $(\mathrm{MOH})$ depicted that the proportion of tuberculosis cases among children and adolescents in Malaysia range between $17 \%$ until $20 \%$ out of total tuberculosis cases with increasing trend from year 2010 until 2015. And exclusively for Kelantan state, the proportion of tuberculosis cases among children and adolescents was $8.4 \%(95 \% \mathrm{Cl}$ : $0.08-0.09)$ out of total cases from year 2012 to 2015 [4].

The nature of tuberculosis occurrence is protean and unique as it can take place in either pulmonary of extrapulmonary sites. Majority of tuberculosis cases affect lungs and known as pulmonary tuberculosis. This form of tuberculosis will disrupt the parenchyma of lungs and lead to structural changes which are demonstrated by abnormal chest $\mathrm{x}$-ray findings, and may be infectious [5]. Around $70-80 \%$ of children and adolescents suffer from pulmonary tuberculosis while the rest are affected by extrapulmonary tuberculosis [6].

A child or adolescent get infected with pulmonary tuberculosis in the exact pattern as an adult, which is through inhalation of a 
mycobacteria-laden aerosol that is disseminated when a contact with active infection coughs, sneezes, or laughs. Droplets must be sufficiently diminutive ( 3 to $5 \mu$ ) to evade the bronchial and bronchiolar ciliated epithelium, and to penetrate to the alveolar level. Once inhaled, the organisms may come to rest in any part of either lung and cause pulmonary tuberculosis $[7,8]$.

There are very little studies regarding the prevalence of severe pulmonary tuberculosis and its associated factors among children and adolescents in Malaysia and worldwide. However, few studies among general population of Malaysia had demonstrated the relatively high prevalence of severe pulmonary tuberculosis with most patients had cavitary changes and advance stages of the disease $[8,10]$. This study aimed to determine the association clinical factors with pulmonary tuberculosis severity among children and adolescents in Kelantan, a northern state of Peninsular Malaysia from 2012 until 2015 using chest radiographic findings on diagnosis as the indicator for severity.

A basic concept of infectious disease particularly applicable to infection with tuberculosis is that the severity of pulmonary tuberculosis is directly proportional to the number of organisms and the virulence of those organisms and inversely proportional to the resistance of the individual host. Thus, malnourished or immunocompromised individuals such as Human Immunodeficiency Virus (HIV) positive individuals exposed multiple times to large doses of virulent organisms may be expected to have the most extensive disease and worst prognosis $[7,11]$. Besides that, other known clinical factors that contributed to severe pulmonary tuberculosis include cigarettes smoking [12, 13], absent Bacillus Calmette-Guerin (BCG) scar [14] and positive sputum Acid-Fast Bacilli (AFB) smear on diagnosis [15].

Imaging plays an important role in the diagnosis and management of tuberculosis. Chest radiographs are used to stratify pulmonary tuberculosis and to assess for asymptomatic active disease [16]. Typically, pulmonary tuberculosis in primary infection demonstrates radiologic findings that include lymphadenopathy, lower lobe lesions, and pleural effusions. Meanwhile, postprimary tuberculosis demonstrates upper lobe lesions, cavitation, and fibrosis [16-18, 20]. The Ghon complex is the pathognomonic macroscopical lesion of primary pulmonary tuberculosis and it results from Mycobacterium tuberculosis initial infection in children. It contains three elements which are the Ghon focus (a small nodular lesion approximately $1 \mathrm{~cm}$ ), lymphadenitis and lymphangitis. These changes can be described as minimal lesion on chest radiographic findings [8, 18-20].

In majority of cases, primary pulmonary tuberculosis has a favorable evolution, with healing by fibrosis and/or calcification resulting in Ranke complex. Otherwise, it evolves into severe form, which includes the local extension of the Ghon focus to an entire lobe or segment, tuberculous bronchopneumonia or even miliary tuberculosis caused by hematogenous dissemination of Mycobacterium tuberculosis locally in the lung or distantly to other extrapulmonary sites. Cavitation is the most important finding in postprimary or severe form of disease. Cavitation implies a high bacillary burden, high infectivity, and is associated with numerous complications including endobronchial spread, tuberculous empyema, hematogenous dissemination, and others. These evolutions and cavitation formation can be referred to moderately or far advanced lesions on chest radiographic findings $[8,18-21]$.

\section{Material and Methods}

This study applied a comparative cross-sectional study design between mild pulmonary tuberculosis and severe pulmonary tuberculosis patients according to chest radiograph changes among children and adolescents. The study was based on retrospective record review and was conducted within three months period starting from January until March 2017 in Tuberculosis and Leprosy Control Unit, Kelantan State Health Department, Malaysia.

The reference populations were all children and adolescents tuberculosis patients in Kelantan and the study samples were children and adolescent pulmonary tuberculosis patients in Kelantan registered in Tuberculosis Information System (TBIS) from 2012 to 2015 who fulfilled study inclusion and exclusion criteria. To control for selection bias, the study had defined inclusion and exclusion criteria. The inclusion criteria were the confirmed cases of tuberculosis who were notified to respective District Health Offices in Kelantan and registered in TBIS from $1^{\text {st }}$ January 2012 to 31st December 2015, diagnosed as pulmonary tuberculosis and aged of 1 year old till 19 years old. Meanwhile, the exclusion criteria were all extrapulmonary tuberculosis cases without concomitant pulmonary tuberculosis.

The outcome or dependent variable was dichotomous variables divided into mild and severe pulmonary tuberculosis cases among children and adolescents. The exposures explored were smoking status, HIV status, presence of BCG scar and pretreatment sputum AFB smear results. All variables were classified into two categories. Smoking status was classified into either non-smoker or smoker. HIV status was either negative or positive. BCG scar was categorized into present or absent. Sputum AFB smear result was categorized as positive or negative.

The sample size was calculated for each variable of associated factors for severity of pulmonary tuberculosis infection among children and adolescent using Power and Sample Size calculation software as well to compare two independent proportions. The largest estimated sample for each comparison group was 144 using the proportion of mild or nonsevere pulmonary tuberculosis children and adolescents in HIV positive patient which was 0.17 based on existing literature [22]. The estimated proportion of $0.06,5 \%$ type 1 error, $80 \%$ power and additional $10 \%$ missing data were applied.

Data were collected from Kelantan TBIS. TBIS is an online registry set up by the Ministry of Health for surveillance purpose of tuberculosis disease in Malaysia. The retrieved information includes clinical information such as cigarettes smoking status, HIV status, presence of BCG scar, sputum AFB smear result, categories of tuberculosis and chest radiographic findings.

In this study, pulmonary tuberculosis severity is classified based on chest radiograph on diagnosis into two groups which were mild (chest radiograph with no lesion or minimal lesion) and severe (chest radiograph with moderate and far advanced lesions). No lesion is defined as chest radiograph with no lesion or cavity on any lung field. Minimal lesion is defined as chest radiograph with small nodular lesion (Ghon focus) approximately $1 \mathrm{~cm}$, lymphadenitis and lymphangitis with no cavity, confined to small parts of one or both lungs but the total extent not 
exceeding the upper zone. Moderately advanced lesion is defined as chest radiograph with dense confluent lesions not exceeding one third of one lung or disseminated slight to moderate density in one or both lungs not exceeding the volume of one lung. If cavity is present, its total diameter should not exceed $4 \mathrm{~cm}$. Far advanced lesion is defined as more extensive chest radiographic lesion than moderately advanced [8, 18]. Pulmonary tuberculosis for this study included smear positive and negative pulmonary tuberculosis; and extrapulmonary tuberculosis with concomitant pulmonary tuberculosis [18].

Statistical Package for Social Science (SPSS) version 22.0 statistical software was used for data entry and analysis. After checking the sample sets of the investigated values for the Kolmogorov-Smirnov distribution normality, it was revealed that the distribution of the investigated parameters were of normal distribution, that is why the methods of parametric statistics with mean and standard deviation calculation were used. Descriptive statistics with frequency and percentages were calculated. Simple and multiple logistic regression analysis were used to determine factors associated with severe pulmonary tuberculosis among children and adolescents. A p-value of less than 0.05 was considered statistically significant.

\section{Results}

Out of 456 total tuberculosis cases among children and adolescents registered in TBIS, 356 (78.0\%) cases were pulmonary tuberculosis; $68(14.9 \%)$ cases were exclusively extrapulmonary tuberculosis; and another $32(7.1 \%)$ cases were pulmonary tuberculosis with concomitant extrapulmonary tuberculosis. Based on the inclusion criteria, only pulmonary tuberculosis and pulmonary tuberculosis with concomitant extrapulmonary tuberculosis cases were included in this study and hence, the total samples regarded as pulmonary tuberculosis were 388 cases.

The severity of pulmonary tuberculosis was based on chest radiograph results done prior to the diagnosis of tuberculosis. Out of the 388 samples, majority of chest radiographs had minimal lesion followed by moderately advanced lesion, no lesion and lastly, far advanced lesion. Details on distribution of chest radiographic findings are shown in Figure 1. Samples with no lesion and minimal lesion on chest radiographs were grouped as mild pulmonary tuberculosis infection (290 cases or $74.7 \%$ ), whereas moderate and far advanced lesion were categorized as severe pulmonary tuberculosis infection (98 cases or $25.3 \%$ ) (Figure 1).

From the total 388 samples with pulmonary tuberculosis, a total of 242 samples were included in this study in which 144 samples obtained via simple random sampling for mild tuberculosis and only 98 samples available for severe tuberculosis. By clinical factors, majority of children and adolescents with severe pulmonary tuberculosis were nonsmoker, HIV negative, present BCG scar, and positive pretreatment sputum smear. Details regarding clinical characteristic are shown in Table 1.

Simple and multiple logistic regression analysis were used to determine the significant associated factors. All significant variables with $p$-value of less than 0.25 from univariable analysis and clinically important variables were chosen for multiple logistic regression analysis. Details regarding factors associated with severe pulmonary tuberculosis among children and adolescents by multiple logistic regression analysis were shown in Table 2.

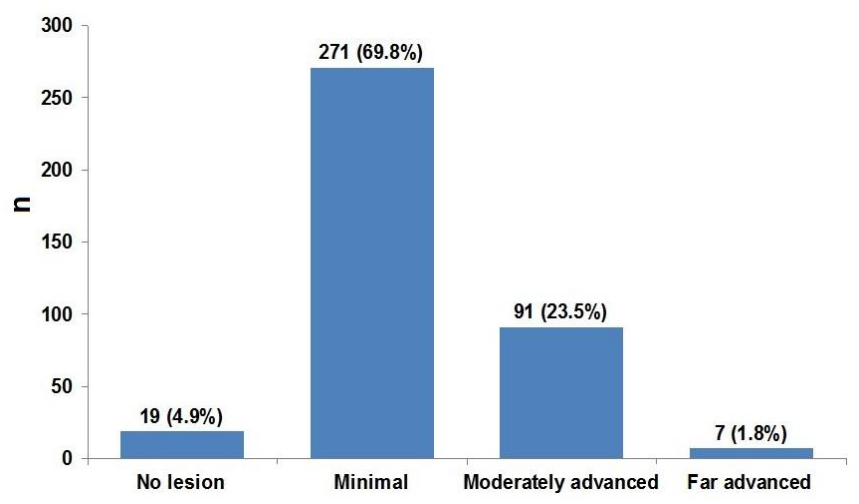

Figure 1. Pulmonary tuberculosis severity by chest radiographic findings on diagnosis among children and adolescents tuberculosis patients ( $n=388)$.

Table 1. Clinical characteristics of pulmonary tuberculosis cases by chest radiographic findings among children and adolescents $(n=242)$

\begin{tabular}{lcc}
\hline Factors & Chest radiographic findings, frequency $(\%)$ \\
\cline { 2 - 3 } & $\begin{array}{c}\text { Mild } \\
(\mathrm{n}=144)\end{array}$ & $\begin{array}{c}\text { Severe } \\
(\mathrm{n}=98)\end{array}$ \\
\hline $\begin{array}{l}\text { Smoking } \\
\text { No }\end{array}$ & $122(84.7)$ & $75(76.5)$ \\
Yes & $22(15.3)$ & $23(23.5)$ \\
HIV infection & & \\
No & $140(97.2)$ & $98(100.0)$ \\
Yes & $4(2.8)$ & $0(0.0)$ \\
BCG Scar & & \\
Present & $136(94.4)$ & $79(80.6)$ \\
Absent & $8(5.6)$ & $19(19.4)$ \\
Sputum smear & & \\
Negative & $68(47.2)$ & $27(27.6)$ \\
Positive & $76(52.8)$ & $71(72.4)$ \\
\hline
\end{tabular}

Table 2. Factors associated with severe pulmonary tuberculosis on diagnosis among children and adolescents in Kelantan 2012-2015 by simple and multiple logistic regression $(\mathbf{n}=\mathbf{2 4 2})$

\begin{tabular}{|c|c|c|c|c|}
\hline Factors & $\begin{array}{c}\text { Crude OR }^{a} \\
(95 \% \mathrm{Cl})\end{array}$ & $\begin{array}{c}\text { Adjusted OR } \\
(95 \% \mathrm{Cl})\end{array}$ & $\begin{array}{c}\text { Wald statistics } \\
\text { (df) }\end{array}$ & $\begin{array}{c}p- \\
\text { value }\end{array}$ \\
\hline \multicolumn{5}{|l|}{ Smoking } \\
\hline No & 1.00 & 1.00 & & \\
\hline Yes & $1.70(1.19,3.26)$ & $1.43(1.21,3.61)$ & $2.61(1)$ & 0.030 \\
\hline \multicolumn{5}{|c|}{ HIV infection } \\
\hline No & 1.00 & 1.00 & & \\
\hline Yes & $0.00(0.00,0.00)$ & $0.00(0.00,0.00)$ & $0.00(1)$ & 0.999 \\
\hline \multicolumn{5}{|c|}{ Sputum smear } \\
\hline Negative & 1.00 & 1.00 & & \\
\hline Positive & $2.35(1.36,4.08)$ & $2.32(1.29,4.13)$ & $8.09(1)$ & 0.004 \\
\hline \multicolumn{5}{|l|}{ BCG scar } \\
\hline Present & 1.00 & 1.00 & & \\
\hline Absent & $1.76(1.27,4.97)$ & $1.24(1.12,8.04)$ & $9.84(1)$ & 0.002 \\
\hline
\end{tabular}

${ }^{\mathrm{a}}$ Simple logistic regression; ${ }^{\mathrm{b}}$ Multiple logistic regression. Forward selection (likelihood ratio) method applied. No multicollinearity and no interaction found. Hosmer Lemeshow test, p-value=0.533. Classification table $74 \%$ correctly classified. Area under Receiver Operating Characteristics (ROC) curve was $66.1 \%$. OR, odds ratio; $\mathrm{Cl}$, confidence interval. 


\section{Discussion}

This is the first study done in Malaysia to describe the characteristic of chest radiographic findings of pulmonary tuberculosis and to determine the association between clinical factors with severe pulmonary tuberculosis infection among children and adolescents.

In this study, mild pulmonary tuberculosis was the most commonly encountered based on chest radiographic findings (74.7\%) and the prevalence of chest radiographic findings related to severe form of pulmonary tuberculosis was low (25.3\%). The result was similar with studies done among children and adolescents in Croatia and Iran. All of these studies showed that the most common lesion was lymphadenopathies in hilomediastinal region without upper lobe involvement or cavitation and radiographic findings favoring the severe form were less common. It was concluded in those studies that the hilar lymphadenopathy was the leading radiographic finding in pulmonary tuberculosis in childhood and adolescence [23-25]. In contrast to our finding, a study among adolescents in South Korea showed that the prevalence of chest radiographic findings related to severe pulmonary tuberculosis was relatively high with almost half of the study samples had lesions with upper lung zone predominance and cavitary lesions [17].

Our study revealed that cigarettes smoking, absence of BCG scar and positive sputum AFB smear on diagnosis were significantly associated with severe pulmonary tuberculosis. In this study, only $23.5 \%$ of children and adolescents with severe pulmonary tuberculosis were found to be smokers. Similar finding was found through study in Papua, Indonesia which reported that $29.5 \%$ of severe pulmonary tuberculosis patients were smokers [15]. Our finding showed that children and adolescents who smoke cigarette were 1.43 times more likely to develop severe pulmonary tuberculosis infection, compared to non-smoking group. Leung et al. (2004) reported similar finding through a study in Hong Kong in which smoking patients were 1.2 times more likely to have moderate or extensive tuberculosis lesion on chest radiographs which indicated severe pulmonary tuberculosis infection [12]. Findings of this study are also in line with another study conducted in Spain which reported that smoking patients were 1.9 times more likely to developed severe pulmonary tuberculosis [13]. Smoking increases the risk of rapid disease progression and severity through few mechanisms. One of the mechanisms is that, smoking reduces the defence on the surface of the respiratory apparatus, alters the mucociliary apparatus through cell destruction and dysfunction, exerts cilio-static and cilio-toxic effects and reduces lysozyme A activity. As a result, germs and toxic substances reach the alveolar tissue in greater numbers. Apart from that, smoking also causes changes in both natural and acquired cell immunity, affecting macrophages and leukocytes. The effect of oxidative stress is particularly important, as it induces apoptosis in both activated and non-activated macrophages, favouring the multiplication of the bacilli and making the process chronic $[13,26,27]$.

In this current study, majority of children and adolescents with severe pulmonary tuberculosis had their BCG scars with $80.6 \%$. Only $19.4 \%$ of them were absent of their BCG scars upon examination. This study found that children and adolescents without BCG scars were 1.24 times more likely to develop severe pulmonary tuberculosis, compared with those with BCG scars. Findings of this study are in line with an unmatched case-control hospital-based study in India among Indian children [28]. They reported that children with absent BCG scar were almost two times higher risk of getting severe tuberculosis as compared to those children with BCG scar (AOR 1.98; 95\% Cl 1.09,3.57; $p=0.023)$. It is reported that the BCG efficacy in preventing severe tuberculosis ranges from $52 \%-84 \%$ [29]. As the immune response against Mycobacterium tuberculosis is less effective among children and adolescents, dedicated vaccination against tuberculosis using BCG in neonates has led to a reduction in incidence of severe childhood tuberculosis and deaths including miliary tuberculosis and tuberculous meningitis [30]. Moreover, recent studies have suggested that BCG vaccination may have a nonspecific beneficial effect on child survival and that a BCG scar may be associated with lower child mortality $[14,31]$. Garly et al. (2003) in a study on association of BCG scar with reduction of child mortality in West Africa found that BCG-vaccinated children with a BCG scar had significantly lower mortality compared with BCG scar-negative children [32]. Therefore, absence of BCG scar could be related to weakened immunity defense against tuberculosis.

We also found significant association between positive pretreatment AFB sputum smear results with severe pulmonary tuberculosis. Positive pre-treatment sputum AFB smear results were observed in majority of children and adolescents with severe pulmonary tuberculosis with $72.4 \%$ were positive. Children and adolescents with positive pre-treatment AFB sputum smear were 2.32 times more likely to develop severe pulmonary tuberculosis, as compared to those with negative pre-treatment AFB sputum smear. Koh et al. (2006) reported that patients with AFB smear positive sputum were significantly associated with extensive lesion on chest radiographs indicating severe pulmonary tuberculosis [33]. A study in Papua, Indonesia was done to see the association between sputum AFB smear status and chest radiograph changes as a predictor for severity of tuberculosis. They reported that cavitary disease on chest radiograph at diagnosis was significantly associated with higher baseline AFB density in sputum $(p=0.007)$ [15]. The number of bacilli depends on the extent of the lesion or the presence of cavitation of lungs in case of pulmonary form of tuberculosis. The larger the cavity or lesion, the larger the amount of bacilli present in patients, and the more likely to infect their contacts. Thus, the grading of a positive smear reflects the extent of lesion in a patient or size of cavitation as well as being directly proportional to the infectiousness of the case [34].

\section{Conclusion}

Pulmonary tuberculosis in children and adolescents most commonly represents as a mild form based on chest radiographic findings either with no lesion or minimal lesion. This study also had demonstrated that the significant clinical determinants for severe pulmonary tuberculosis were tobacco smoking, absent BCG scar and positive pre-treatment AFB sputum smear. By highlighting these important clinical determinants severe pulmonary tuberculosis infection, it will assist and guide health authorities to design a better and comprehensive plan for the national tuberculosis control programme, focusing more attention towards children and adolescents group. Consequently, dynamic transmission of tuberculosis in our community could be prevented.

\section{Limitations}

Small sample size for HIV positive patients was one of the limitations of this study because small sample size would limit the 
findings on its association with severe pulmonary tuberculosis. Further study with larger sample size is recommended to look into this association, and in order to ensure adequate sample size for HIV positive patients is obtained, HIV endemic setting or larger settings such as country level is recommended.

\section{Acknowledgments}

The authors would like to thank the Director General of Health Malaysia for allowing us to do data collection from TBIS database for tuberculosis in which ethical approval was obtained from Ministry of Health. Our gratitude also goes to the Kelantan Tuberculosis and Leprosy Control Unit for their assistance during data collection.

\section{Conflict of interest}

The authors declare that they have no conflict of interest. This research received no funding from any party.

\section{Ethical approval}

All procedures performed in studies involving human participants were in accordance with the ethical standards of the institutional and/or national research committee and with the 1964 Helsinki declaration and its later amendments or comparable ethical standards. For this type of study formal consent is not required. The study was approved by the Human Research and Ethics Committee, Universiti Sains Malaysia USM/JEPeM/16120592 and the Medical Review and Ethical Committee from National Institute of Health, Ministry of Health Malaysia NMRR-162348-33521 (IIR).

\section{References}

1. Zaman K. Tuberculosis: a global health problem. J Health Popul Nutr 2010; 28(2): 111-113. https://www.ncbi.nlm.nih.gov/pubmed/20411672.

2. Global Tuberculosis Report 2016. Switzerland: World Health Organization, 2016: 5, 12. http://apps.who.int/medicinedocs/documents/s23098en/s23098en.pdf

3. Department of Statistics. Population and housing census of Malaysia: Population distribution and basic demographic characteristics 2010. Malaysia: Department of Statistics, 2010; 85 p. https://www.statistics.gov.my/censusatlas/images/ReligionBM.pdf.

4. Awang $\mathrm{H}$, Husain NRN, Abdullah $\mathrm{H}$. Pediatric tuberculosis in a Northeast State of Peninsular Malaysia: diagnostic classifications and determinants. Oman Med J 2019; 34(2): 110-117. https://doi.org/10.5001/omj.2019.22.

5. Core curriculum on tuberculosis: what the clinician should know. Sixth Edition. Centers for Disease Control Prevention, 2013; 6: 21-42. https://www.cdc.gov/tb/education/corecurr/pdf/corecurr_all.pdf.

6. Childhood TB Training Tookit. Module 1: Epidemiology of Childhood TB. Switzerland: World Health Organization, 2014: 2. https://www.who.int/tb/challenges/ChildhhoodTB section1.pdf?ua=1

7. Agrons GA, Markowitz RI, Kramer SS. Pulmonary tuberculosis in children. Semin Roentgenol 1993; 28(2): 158-172. https://doi.org/10.1016/S0037-198X(05)80105-1.

8. Leung AN. Pulmonary tuberculosis: the essentials. Radiology 1999; 210(2): 307-322. https://doi.org/10.1148/radiology.210.2.r99ja34307.

9. Nantha S. A review of tuberculosis research in Malaysia. Med J Malaysia 2014; 69(suppl A): 88-102. http://www.emjm.org/2014/supplement-A/tuberculosis-research.pdf.

10. William T, Parameswaran U, Lee WK, Yeo TW, Anstey NM, Ralph AP. Pulmonary tuberculosis in outpatients in Sabah, Malaysia: advanced disease but low incidence of HIV co-infection. BMC Infect Dis 2015; 15(1): 32. https://doi.org/10.1186/s12879-015-0758-6.

11. Burman W, Weis S, Vernon A, Khan A, Benator D, Jones B, et al. Frequency, severity and duration of immune reconstitution events in HIV-related tuberculosis. The international journal of tuberculosis and lung disease 2007; 11(12):

https://www.ncbi.nlm.nih.gov/pubmed/18229435.

1282-1289.

12. Leung CC, Li T, Lam TH, Yew WW, Law WS, Tam CM, et al. Smoking and tuberculosis among the elderly in Hong Kong. Am J Respir Crit Care Med 2004; 170(9): 1027-1033. https://doi.org/10.1164/rccm.200404$\underline{5120 C .}$

13. Altet-Gômez MN, Alcaide J, Godoy P, Romero MA, Hernández del Rey I. Clinical and epidemiological aspects of smoking and tuberculosis: a study of 13038 cases. Int J Tuberc Lung Dis 2005; 9(4): 430-436. https://www.ncbi.nlm.nih.gov/pubmed/15830749.

14. Tidjani $\mathrm{O}$, Amedome A, ten Dam HG. The protective effect of BCG vaccination of the newborn against childhood tuberculosis in an African community. Tubercle 1986; 67(4): 269-281. https://doi.org/10.1016/0041-3879(86)90016-4.

15. Ralph AP, Ardian M, Wiguna A, Maguire GP, Becker NG, Drogumuller $G$, et al. A simple, valid, numerical score for grading chest $x$-ray severity in adult smear-positive pulmonary tuberculosis. Thorax 2010; 65(10): 863-869. http://doi.org/10.1136/thx.2010.136242.

16. Nachiappan AC, Rahbar K, Shi X, Guy ES, Mortani Barbosa EJ Jr, Shroff GS, et al. Pulmonary tuberculosis: role of radiology in diagnosis and management. Radiographics 2017; 37(1): $52-72$ https://doi.org/10.1148/rg.2017160032.

17. Koh WJ, Jeong YJ, Kwon OJ, Kim HJ, Cho EH, Lew WJ, et al. Chest radiographic findings in primary pulmonary tuberculosis: observations from high school outbreaks. Korean J Radiol 2010; 11(6): 612-617. https://doi.org/10.3348/kjr.2010.11.6.612.

18. Ministry of Health. Clinical Practice Guidelines: Management of Tuberculosis. Malaysian Ministry of Health, 2012: 83-84. http://www.moh.gov.my/moh/attachments/8612.pdf.

19. Marais BJ, Gie RP, Schaaf HS, Starke JR, Hesseling AC, Donald PR, et al. A proposed radiological classification of childhood intra-thoracic tuberculosis. Pediatr Radiol 2004; 34(11): 886-894. https://doi.org/10.1007/s00247-004-1238-0.

20. Leung AN, Müller NL, Pineda PR, FitzGerald JM. Primary tuberculosis in childhood: radiographic manifestations. Radiology 1992; 182(1), 87-91. https://doi.org/10.1148/radiology.182.1.1727316.

21. McAdams HP, Erasmus J, Winter JA. Radiologic manifestations of pulmonary tuberculosis. Radiol Clin North Am 1995; 33(4): 655-678. https://www.ncbi.nlm.nih.gov/pubmed/7610237.

22. Giri PA, Deshpande JD, Phalke DB. Prevalence of pulmonary tuberculosis among HIV positive patients attending antiretroviral therapy clinic. N Am J Med Sci 2013; 5(6): 367-370. https://doi.org/10.4103/1947-2714.114169.

23. Milković D, Richter D, Zoricić-Letoja I, Raos M, Koncul I. Chest radiography findings in primary pulmonary tuberculosis in children. Coll Antropol 2005; 29(1): 271-276 https://www.ncbi.nlm.nih.gov/pubmed/16117335.

24. Khatami A, Sabouri S, Ghoroubi J, Rasouli N, Gorji FA. Radiological findings of pulmonary tuberculosis in infants and young children. Iranian Journal of Radiology 2008; 6(1): 231-234. https://web.a.ebscohost.com/abstract?direct=true\&profile=ehost\&sc ope $=$ site\&authtype $=$ crawler\&jrnl=17351065\&AN $=40825774 \& \mathrm{~h}=$ ev9ru ZELk6iw1U0LcQ9W2DZI7|\%2fy7NNZ4nBH15w5xRcD\%2b7zZ9gNeMXTz RGprEDuikHfZIBEh9mItLnPBcJLxsA\%3d\%3d\&crl=c\&resultNs=AdminWe bAuth\&resultLocal=ErrCrINotAuth\&crlhashurl=login.aspx\%3fdirect\%3d true\%26profile\%3dehost\%26scope\%3dsite\%26authtype\%3dcrawler\%2 6jrnl\%3d17351065\%26AN\%3d40825774.

25. Boloursaz MR, Khalilzadeh S, Baghaie N, Khodayari AA, Velayati AA. Radiologic manifestation of pulmonary tuberculosis in children admitted in pediatric ward-Massih Daneshvari Hospital: a 5-year retrospective study. Acta Med Iran 2010; 48(4): 244-249. https://www.ncbi.nlm.nih.gov/pubmed/21279938.

26. Sopori M. Effects of cigarette smoke on the immune system. Nat Rev Immunol 2002; 2(5): 372-377. https://doi.org/10.1038/nri803. 
27. Stämpfli MR, Anderson GP. How cigarette smoke skews immune responses to promote infection, lung disease and cancer. Nat Rev Immunol 2009; 9(5): 377-384. https://doi.org/10.1038/nri2530.

28. Kumar P, Kumar R, Srivastava K, Kumar M. Protective role of BCG vaccination against tuberculous meningitis in Indian children: a reappraisal. Natl Med J India 2005; 18(1): 7-11. https://www.ncbi.nlm.nih.gov/pubmed/15835483.

29. Thilothammal N, Krishnamurthy P, Runyan DK, Banu K. Does BCG vaccine prevent tuberculous meningitis? Arch Dis Child 1996; 74(2): 144-147. http://doi.org/10.1136/adc.74.2.144.

30. Waako J, Verver S, Wajja A, Ssengooba W, Joloba ML, Colebunders R, et al. Burden of tuberculosis disease among adolescents in a rural cohort in Eastern Uganda. BMC Infect Dis 2013; 13: 349. https://doi.org/10.1186/1471-2334-13-349.

31. Roth A, Gustafson P, Nhaga A, Djana Q, Poulsen A, Garly ML, et al. BCG vaccination scar associated with better childhood survival in GuineaBissau. Int J Epidemiol 2005; 34(3): 540-547. https://doi.org/10.1093/ije/dyh392.

32. Garly ML, Martins $C L$, Balé $C$, Baldé $M A$, Hedegaard $K L$, Gustafson $P$, et al. BCG scar and positive tuberculin reaction associated with reduced child mortality in West Africa: a nonspecific beneficial effect of BCG? Vaccine 2003; 21(21-22): 2782-2790. https://doi.org/10.1016/S0264410X(03)00181-6.

33. Koh WJ, Yu CM, Suh GY, Chung MP, Kim H, Kwon OJ, et al. Pulmonary TB and NTM lung disease: comparison of characteristics in patients with AFB smear-positive sputum. Int J Tuberc Lung Dis 2006; 10(9): 1001-1007. https://www.ncbi.nlm.nih.gov/pubmed/16964791.

34. Rajpal S, Dhingra VK, Aggarwal JK. Sputum grading as predictor of treatment outcome in pulmonary tuberculosis. Ind J Tub 2002; 49(3): 139-142. http://medind.nic.in/ibr/t02/i3/ibrt02i3p139.pdf.

\section{Authors:}

Hafizuddin Awang - MD, MPH, Public Health Medical Officer, Department of Community Medicine, Universiti Sains Malaysia, Kelantan, Malaysia. https://orcid.org/0000-0001-5522-7534.

Nik Rosmawati Nik Husain - MD, MComm.Med, PhD, Public Health Medicine Specialist, Department of Community Medicine, Universiti Sains Malaysia, Kelantan, Malaysia. https://orcid.org/0000-0002-6798-0838.

Hasniza Abdullah - MD, MComm.Med, Principal Assistant Director, Tuberculosis and Leprosy Control Unit, Kelantan State Health Department, Kelantan, Malaysia. https://orcid.org/0000-0002-7294-9800. 